Western University Scholarship@Western

Management and Organizational Studies

Management and Organizational Studies

Publications

Department

2013

\title{
When Do (and Don't) Normative Appeals Influence Sustainable Consumer Behaviors?
}

Katherine White

University of British Columbia

Bonnie Simpson

Western University, bonnie.simpson@uwo.ca

Follow this and additional works at: https://ir.lib.uwo.ca/mospub

Part of the Business Administration, Management, and Operations Commons, and the Work, Economy and Organizations Commons

Citation of this paper:

White, Katherine and Simpson, Bonnie, "When Do (and Don't) Normative Appeals Influence Sustainable Consumer Behaviors?" (2013). Management and Organizational Studies Publications. 7.

https://ir.lib.uwo.ca/mospub/7 


\section{When Do (and Don't) Normative Appeals Influence Sustainable Consumer Behaviors?}

The authors explore how injunctive appeals (i.e., highlighting what others think one should do), descriptive appeals (i.e., highlighting what others are doing), and benefit appeals (i.e., highlighting the benefits of the action) can encourage consumers to engage in relatively unfamiliar sustainable behaviors such as "grasscycling" and composting. Across one field study and three laboratory studies, the authors demonstrate that the effectiveness of the appeal type depends on whether the individual or collective level of the self is activated. When the collective level of self is activated, injunctive and descriptive normative appeals are most effective, whereas benefit appeals are less effective in encouraging sustainable behaviors. When the individual level of self is activated, self-benefit and descriptive appeals are particularly effective. The positive effects of descriptive appeals for the individual self are related to the informational benefits that such appeals can provide. The authors propose a goal-compatibility mechanism for these results and find that a match of congruent goals leads to the most positive consumer responses. They conclude with a discussion of implications for consumers, marketers, and public policy makers.

Keywords: normative appeals, sustainability, injunctive norms, descriptive norms, individual self, collective self

$\mathbf{W}$ hen encouraging consumers to engage in sustainable behaviors, marketers and public policy advocates often capitalize on the persuasive power of social norms (e.g., Cialdini, Reno, and Kallgren 1990; Goldstein, Cialdini, and Griskevicius 2008). For example, World Wildlife Fund's (WWF) Earth Hour energy conservation campaign highlights descriptive norms (i.e., norms reflecting what others are doing) by posting others' positive actions online and suggesting that others are engaging in the behavior ("the world's largest single campaign for the planet" [WWF 2012a]). The campaign also highlights injunctive norms (i.e., norms reflecting what others think should be done) by suggesting that people should be engaging in sustainable conservation behaviors (e.g., "We only have one planet. You should help protect it." [WWF 2012b]). The current research examines the conditions under which different types of appeals are most effective.

Marketers have called for additional research regarding the predictors of sustainable, prosocial consumer behaviors (Menon and Menon 1997; Mick 2006), in part because it is often difficult to encourage consumers to behave in a sustainable manner (Costanzo et al. 1986; Luchs et al. 2010).

Katherine White is Associate Professor of Marketing, Sauder School of Business, University of British Columbia (e-mail: Katherine.White@ sauder.ubc.ca). Bonnie Simpson is a doctoral candidate in Marketing, Haskayne School of Business, University of Calgary (e-mail: bonniejeansimpson@hotmail.com). The authors are grateful for funding from the Social Sciences and Humanities Council of Canada and for collaboration with Dave Merredew and others at the City of Calgary. They also thank Jennifer Argo, Darren W. Dahl, Lea Dunn, Joey Hoegg, and John Peloza for helpful comments on a previous version of this article. Stephen Nowlis served as area editor for this article.
An issue that arises in contexts of sustainable consumption behaviors is that consumers often tend to resist engaging in activities that involve some cost to the individual-level self (e.g., additional time, increased effort, behavioral change), despite the goal of promoting a more societal, other-focused good (e.g., more sustainable practices and outcomes). Such a dichotomy leads to the question whether self-benefit appeals (that highlight benefits of prosocial actions to the individual self; Nolan et al. 2008; White and Peloza 2009) or normative appeals (that highlight social norms regarding what others are doing or what others think should be done; Cialdini, Kallgren, and Reno 1991; Cialdini, Reno, and Kallgren 1990) will be most effective in influencing sustainable behaviors. This research examines when and why these different types of appeals will most effectively encourage sustainable intentions and behaviors. We do so by examining the moderating role of the level of the self at which the appeal is considered. That is, while marketers sometimes appeal to the level of the individual self (e.g., "you can help protect it" [WWF 2012a, emphasis added]), they can also appeal to the collective self (e.g., "Think of what can be achieved when we all come together for a common cause" [WWF 2012b, emphasis added]).

Encouraging people to engage in environmentally sustainable behaviors is arguably one of the biggest challenges facing our world today (Organisation for Economic Cooperation and Development [OECD] 2008; Peattie 2010). Despite the efforts of public policy makers to encourage sustainable waste management practices, consumers generated an estimated 243 million tons of garbage (or approximately 4.3 pounds of waste per person per day) in the United States alone in 2009 (U.S. Environmental Protection 
Agency [EPA] 2011). One estimate suggests that American consumers discard most materials (approximately 76\%) into landfills after using them only once, rather than engaging in alternative forms of waste management such as recycling, composting, or reusing items (EPA 2011). The current research focuses on two sustainable consumer waste disposal behaviors, "grasscycling" and composting. Grasscycling involves leaving grass clippings on the lawn so they can decompose and return valuable nutrients to the soil rather than bagging them and leaving them out for garbage collection (Cobern et al. 1995). Composting refers to the purposeful biodegradation of organic matter such as food waste rather than disposing of this waste in the garbage. We propose a framework that highlights when different types of appeals to engage in these sustainable consumer behaviors will be most successful.

\section{Contributions of the Current Research}

The current research makes several notable contributions to the literature. First, although a large body of research has examined the effects of normative appeals on behavior (e.g., Cialdini, Kallgren, and Reno 1991; Cialdini, Reno, and Kallgren 1990; Fisher and Ackerman 1998; Schultz et al. 2007), there is a paucity of work examining moderators of normative influence. We examine the activation of the individual, independent self versus activation of the collective, interdependent self as a moderator of normative influence. In doing so, we are able to determine when normative appeals will be most effective and when they can lead to unfavorable effects. Notably, although benefit appeals and normative appeals are commonly used in examinations of prosocial behaviors, research has rarely compared them within the same study (for an exception, see Nolan et al. 2008) and has not examined moderators of their effects in the same context. Importantly, we do so across four studies including a field study, examining meaningful real-world sustainable behaviors.

Second, we make another contribution to the existing literature by proposing a goal-compatibility account of the findings. We suggest that when the collective (individual) self is activated and an injunctive or descriptive (benefit or descriptive) appeal is presented, salient group-level (individuallevel) goals will be congruent with the type of appeal. Importantly, we also demonstrate that reported individualand group-level goals mediate the effects in predicted ways. This builds on previous work that highlights matching effects in the domains of regulatory focus (e.g., Lee and Aaker 2004) and construal level (e.g., White, MacDonnell, and Dahl 2011) to show that a match in terms of individual versus collective goals can have positive downstream behavioral consequences.

Third, we further test our goal-compatibility account by examining the moderating role of a theoretically relevant construct: autonomy. In particular, we suggest that when the individual self is activated and an injunctive appeal is made, less positive sustainable intentions may arise due to goal incompatibility. Because injunctive appeals have the potential to threaten a person's sense of autonomy (i.e., they can threaten a person's ability to act and choose freely), they are not compatible with the activation of the individual level of the self. Our framework proposes and finds that a manipulation that enhances the consumer's felt autonomy (vs. a control condition) resolves the goal incompatibility, thereby leading to more favorable reactions to an injunctive appeal under conditions in which the individual level of self is activated.

Finally, we highlight the importance of goal compatibility by examining the moderating role of ambiguity. In particular, we suggest that in contexts in which the individual self is activated, descriptive appeals provide valuable information because they suggest appropriate actions in which the person might engage. However, we propose that this informational value of descriptive appeals emerges only when the context is ambiguous or unfamiliar. As such, we predict and find that when the individual self is activated, descriptive appeals are particularly effective in influencing sustainable consumer intentions and behaviors when the action is relatively ambiguous. We now turn to a discussion of our conceptual framework.

\section{Appeal Type and Sustainable Consumer Behavior}

As noted previously, marketers commonly use two routes to encouraging consumers to engage in prosocial behaviors. The first is to use self-benefit appeals that communicate benefits to the individual self as a result of engaging in the behavior (e.g., Brunel and Nelson 2000; Nolan et al. 2008; White and Peloza 2009). Consumers are more likely to engage in prosocial actions when the request for help is accompanied by some form of benefit to the self (Holmes, Miller, and Lerner 2002). In the domain of energy conservation, for example, a benefit appeal might emphasize money savings to the homeowner. The second route is to highlight the social aspects of engaging in the behavior, which is often accomplished through the use of social norms. Cialdini and his colleagues (Cialdini, Kallgren, and Reno 1991; Cialdini, Reno, and Kallgren 1990; Reno, Cialdini, and Kallgren 1993) propose that norms are best divided into two categories: "descriptive norms," defined as norms that convey information regarding what others commonly do, and "injunctive norms," defined as norms that convey information regarding what others approve and disapprove of. As the example at the outset of the article suggests, energy conservation can be promoted as something other people are doing (descriptive norm) or as something other people think people should be doing (injunctive norm).

Research suggests that both descriptive norms and injunctive norms positively influence sustainable consumption behaviors (Cialdini, Kallgren, and Reno 1991; Cialdini, Reno, and Kallgren 1990; Nolan et al. 2008; Reno, Cialdini, and Kallgren 1993; Schultz et al. 2007). Both types of social norms can be more influential than factors people intuitively believe will affect their behaviors, such as the provision of benefits to the self (Nolan et al. 2008). Importantly, however, there is a scarcity of research examining the moderators of normative influence. The little work that has investigated the moderating effects of normative mes- 
sages on sustainable behaviors indicates that when a descriptive norm is combined with reference to the same setting (e.g., others staying in the same hotel room; Goldstein, Cialdini, and Griskevicius 2008) or with an injunctive message (Schultz et al. 2007), normative communications can be particularly influential. The current research examines the comparative effectiveness of descriptive norm appeals, injunctive norm appeals, and self-benefit appeals and highlights the conditions under which each will be most (least) effective.

\section{The Role of the Individual and Collective Levels of Self}

This research proposes a novel moderator of normative influence: whether the message is considered at an individual or a collective level of the self (Brewer and Gardner 1996; Tajfel and Turner 1986). Social identity theorists suggest that identity is composed of two levels: personal identity (i.e., identity related to a person's individual sense of self) and social identity (i.e., the various identities that are related to groups to which a person belongs or is affiliated) (Brewer 1991; Tajfel and Turner 1986). Self-construal theory (Singelis 1994) also points to the notion that selves can be viewed as more bounded, separate, and individualistic (independent self-construal) or more interconnected and collectivistic (interdependent self-construal).

Although important individual differences exist in terms of the relative degree to which a person defines the self at the level of the individual, independent self or at the level of collective, interdependent self (Markus and Kitayama 1991; Singelis 1994; Triandis 1989), people are flexible and dynamic in their construal of the self. That is, sometimes the context activates more individual-level aspects of the self, whereas other times the situation activates collectivelevel self aspects (Brewer and Gardner 1996; Gardner, Gabriel, and Lee 1999). When the individual level of self is activated, people tend to focus more on personal goals and standards, whereas when the collective level of the self is activated, people tend to focus on group goals and the standards held by others (e.g., Gardner, Gabriel, and Lee 1999; Lee, Aaker, and Gardner 2000; White and Argo 2011).

We propose that the effectiveness of the different types of appeals (injunctive norm, descriptive norm, and selfbenefit) will be moderated by whether a more individual or collective level of the self is activated. Furthermore, we suggest that this result will be driven by a goal-compatibility effect, wherein compatible goals stemming from the combination of the activation of the self and the appeal type will lead to the most positive sustainable consumer intentions and behaviors. For example, we predict that when the collective self is activated, consumers will exhibit particularly positive sustainable behaviors in response to appeals that highlight either injunctive or descriptive norms. This is because behaving consistently with injunctive norms meets interpersonal goals such as belonging to an in-group (Smith and Louis 2008) and fulfilling social obligations (Jacobson, Mortensen, and Cialdini 2011). Such goals have been shown to be more relevant to those who are more interdependent (Markus and Kitayama 1991). Likewise, descrip- tive norms that focus on what others are doing should activate group-level goals, which are consistent with a more interdependent, collective mind-set (Markus and Kitayama 1991; Singelis 1994). In summary, it is predicted that when the collective-level self is activated, both injunctive and descriptive norms should positively influence sustainable intentions and behaviors. However, a benefit appeal is likely to be much less effective when the collective self is primed. This is because benefit appeals are not goal congruent with activation of the collective self. Thus:

$\mathrm{H}_{1}$ : When the collective level of self is activated, consumers exhibit more positive sustainable intentions and behaviors in response to descriptive norm and injunctive norm appeals, compared with the benefit appeals and control conditions (i.e., an information-only message or no message).

When the individual level of self is activated, particularly positive behaviors may arise in response to self-benefit appeals. This is because people with an activated individual level of self tend to focus on individual-level goals and self standards (e.g., Gardner, Gabriel, and Lee 1999; White and Argo 2011). Thus, a communication that promotes selfbenefits would be congruent with such individual-level goals. However, following from our goal-compatibility account, we propose that when the individual self is primed, consumer responses to injunctive and descriptive norms will diverge. An injunctive normative appeal focuses on collective "oughts," or the standards set forth by others (Cialdini, Kallgren, and Reno 1991). When the individual self is activated, consumers might be resistant to injunctive norms because their "ought" nature is inconsistent with individual-level goals in a way that potentially limits the individual's autonomy (i.e., injunctive messages threaten a person's ability to act and choose freely). Indeed, research suggests that people will exhibit negative attitudes when their autonomy is threatened in some way (Brehm 1966; Brehm and Brehm 1981; Liu, Smeesters, and Vohs 2012). It seems likely, then, that reactions to threats to autonomy may be particularly pronounced for those with the individual level of self activated. Although this notion has not been directly tested, research indicates that threats to distinctiveness (by having one's choice copied by a similar other) lead to negative responses for those who have an independent self activated (White and Argo 2011). Thus, we predict that threats to autonomy (communicated through an injunctive norm) might similarly lead to less positive reactions among those for whom the individual self is activated, as a result of goal incompatibility.

Conversely, we propose that under certain conditions, consumers may exhibit positive reactions to descriptive norms when the individual level of self is activated. This might seem counterintuitive at first because descriptive norms focus on the actions of the group rather than the individual person (Cialdini, Reno, and Kallgren 1990). However, we suggest that descriptive norms can provide important information to the self about how to behave appropriately and that following descriptive norms often leads to desirable outcomes for the individual (Cialdini and Trost 1998). Indeed, according to Cialdini, Reno, and Kallgren (1990, p. 1015), descriptive norms provide evidence as 
to "what will likely be an effective and adaptive action." Consistent with this informational view of descriptive norms, people are particularly likely to use descriptive information when the situation is somewhat novel, ambiguous, or uncertain (e.g., Cialdini 2001; Griskevicius et al. 2006). Furthermore, more recent research shows that priming words related to descriptive norms (e.g., "typical," "widespread") activates thoughts of accuracy more so than does priming injunctive or neutral words (Jacobson, Mortensen, and Cialdini 2011). Therefore, we propose that following descriptive norms confers benefits to the self, in that they provide relevant information regarding how to behave, particularly when the activity is ambiguous or uncertain. Note that the behaviors of interest in the current research-grasscycling and composting - are viewed as being "unfamiliar" and "ambiguous" (see Study 4 pretest). Thus, in the domains of grasscycling and composting, we predict that when the individual level of self is activated, descriptive norms will be goal compatible in that they provide important information to the self. Consistent with our goal-compatibility account, then, when the individual self is activated, descriptive appeals will lead to more positive consumer intentions and behaviors than will injunctive appeals (for a conceptual framework, see Figure 1). In summary:

$\mathrm{H}_{2}$ : When the individual level of the self is activated, consumers exhibit more positive sustainable intentions and behaviors in response to benefit appeals and descriptive appeals, compared with injunctive appeals or a control condition (i.e., an information-only message or no message).

We examine our propositions across four studies. In Study 1 , we test $\mathrm{H}_{1}$ and $\mathrm{H}_{2}$ in the domain of grasscycling attitudes. In Study 2, we examine the hypotheses in the context of a field experiment that assesses city residents' actual grasscycling behaviors. In Studies 3 and 4, we examine additional predictions stemming from our goal compatibility account. In Study 3, we show that less favorable reactions to injunctive appeals when the individual self is activated are related to threats to individual autonomy. In Study 4 , we show that more favorable reactions to descriptive appeals when the individual self is activated are related to the information descriptive appeals can provide when the activity is ambiguous (vs. unambiguous).

FIGURE 1

\section{Conceptual Framework: Influence of Appeal Type on Sustainable Attitudes and Behaviors}

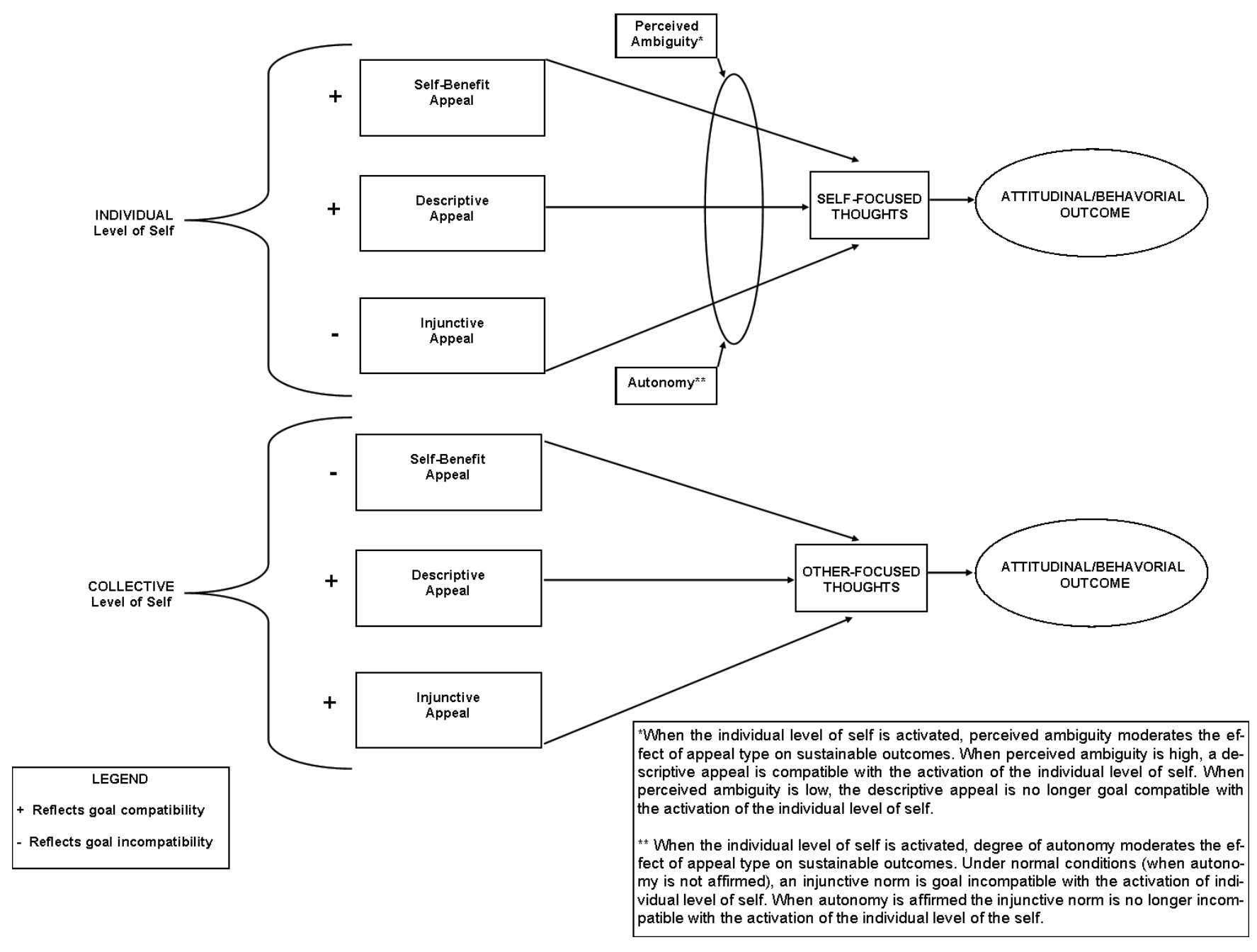




\section{Study 1: Consumer Attitudes Toward Grasscycling}

In Study 1, we test our predictions in the domain of attitudes toward grasscycling. Following from the framework described previously, we propose that when the collective self is activated, consumers will be most responsive to injunctive and descriptive norm appeals, whereas benefit appeals may be less effective. In contrast, when the individual self is activated, consumers will be most responsive to benefit and descriptive appeals, with injunctive appeals being less effective.

\section{Method}

We used a 2 (level of self: individual vs. collective) $\times 3$ (message appeal: descriptive vs. injunctive vs. benefit) between-subjects design, and we included a control group that received information only (seven experimental conditions in total). We achieved the level of self manipulation by varying the text in the advertisement (see Appendix A). In the collective condition, the text used collective pronouns (e.g., "our," "we"). In the individual condition, the pronouns were independent (focusing on "you" and "your"). A pretest indicated that the term "you" (vs. "we") does indeed lead people to focus more on the individual self. We manipulated the appeal by varying the message to include statements describing self-benefits (e.g., "Think about the benefits for you as an individual if you grasscycle"), injunctive norms (e.g., "Your neighbors want you to grasscycle"), or descriptive norms (e.g., "Join others in your community in grasscycling"). In the control condition, participants read an appeal that provided information about grasscycling only.

A community sample of people who indicated that they do have lawns $(n=119)$ completed a paper-and-pencil version of the questionnaire and were randomly assigned to view one of the seven possible messages. We used a convenience sample taken from employees of three organizations (a university, a nonprofit company, and a for-profit company; age range 18-66 years). They reported their attitudes toward grasscycling on a series of nine-point attitude scales ("unfavorable/favorable," "dislike/like," and bad/good"; $\alpha=$ .89; adapted to the grasscycling context from White and Dahl 2006). Participants also completed manipulation checks for message appeal including benefit ("The advertisement that you viewed asked you to consider the benefits to yourself if you grasscycle," and "The advertisement that you viewed asked you to consider what you might get out of grasscycling" $[\mathrm{r}=.86]$ ), injunctive ("The advertisement that you viewed asked you to consider what others in your community approve of," and "The advertisement that you viewed asked you to consider what others want you to do" $[\mathrm{r}=.76]$ ), and descriptive ("The advertisement that you viewed asked you to consider what others are doing"). Finally, participants completed demographic items. There was no main effect of gender and no interactions with the other independent variables in this study. This is true across all the lab studies in which demographic variables were assessed, and so this is not discussed further.

\section{Results}

Manipulation checks. A level of self $\times$ message appeal analysis of variance (ANOVA) on the benefit manipulation check confirmed that a main effect only emerged for message appeal $(\mathrm{F}(1,95)=5.17, p<.01)$. Planned contrasts (Howell 1997; see also McFarland and Miller 1994; White, MacDonnell, and Dahl 2011; White and Peloza 2009) revealed that those in the benefit condition viewed the appeal as more benefit oriented $(\mathrm{M}=5.79)$ than did those in the injunctive $(\mathrm{M}=4.69 ; \mathrm{t}(95)=2.78, p<.01)$ and descriptive $(\mathrm{M}=4.71 ; \mathrm{t}(95)=2.76, p<.01)$ appeal conditions. Similar analysis on the injunctive norm check also revealed a main effect for message appeal $(\mathrm{F}(1,95)=13.29, p<$ $.001)$. Those in the injunctive condition viewed the appeal as being more injunctive $(\mathrm{M}=5.11)$ than those in the descriptive $(\mathrm{M}=4.18 ; \mathrm{t}(95)=2.51, p<.05)$ and benefit $(\mathrm{M}=$ $3.19 ; \mathrm{t}(95)=4.29, p<.001)$ conditions. Finally, analysis on the descriptive-norm manipulation check revealed a main effect for message appeal $(\mathrm{F}(1,95)=17.94, p<.001)$. Those in the descriptive condition viewed the appeal as being more descriptive $(M=4.98)$ than those in the benefit $(\mathrm{M}=2.92 ; \mathrm{t}(95)=5.97, p<.001)$ and injunctive $(\mathrm{M}=3.93$; $\mathrm{t}(95)=3.04, p<.01)$ conditions.

Grasscycling attitudes. A level of self $\times$ message appeal ANOVA on grasscycling attitudes revealed the anticipated interaction $(\mathrm{F}(2,95)=9.30, p<.001)$. To analyze all conditions, including the control group, we also conducted a oneway ANOVA $(\mathrm{F}(6,111)=3.77, p<.01$; Figure 2$)$. Planned contrasts confirmed that, as $\mathrm{H}_{1}$ predicted, when a collective level of self was activated, the injunctive appeal $(\mathrm{M}=6.17$, $\mathrm{SD}=.91 ; \mathrm{t}(111)=3.08, p<.01)$ and descriptive appeal $(\mathrm{M}=$ $6.06, \mathrm{SD}=.80 ; \mathrm{t}(111)=2.82, p<.01)$ led to more positive attitudes than the benefit appeal $(\mathrm{M}=4.85, \mathrm{SD}=1.59)$. When the collective level of self was activated, injunctive $(\mathrm{t}(111)=2.41, p<.05)$ and descriptive $(\mathrm{t}(111)=2.15, p<$ $.05)$ appeals led to more positive attitudes than did the control condition $(\mathrm{M}=5.14, \mathrm{SD}=1.40)$. As we anticipated, the benefit appeals did not significantly differ from the control condition $(\mathrm{t}(111)=.70$, not significant $[\mathrm{n} . \mathrm{s}]$.$) .$

\section{FIGURE 2 \\ Attitudes Toward Grasscycling as a Function of Level of Self and Appeal Type}

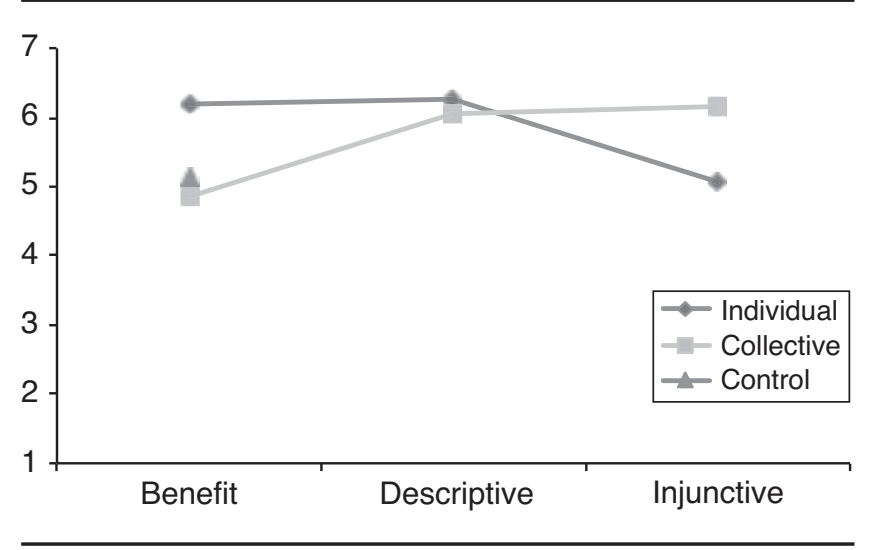

Notes: Scores reported are condition means. 
As $\mathrm{H}_{2}$ predicted, when the individual level of self was activated, participants reported more positive attitudes resulting from the benefit appeal $(\mathrm{M}=6.20 ; \mathrm{SD}=1.03)$ than from the individual/injunctive $(\mathrm{M}=5.06, \mathrm{SD}=1.28 ; \mathrm{t}(111)=2.71$, $p<.01)$ and the control $(\mathrm{M}=5.14, \mathrm{SD}=1.40 ; \mathrm{t}(111)=$ $2.52, p<.05)$ conditions. When the individual self was activated, the descriptive appeal led to more positive attitudes $(\mathrm{M}=6.27, \mathrm{SD}=1.01)$ than did the injunctive appeal $(\mathrm{M}=$ $5.06 ; \mathrm{t}(111)=2.75, p<.01)$ and the control $(\mathrm{t}(111)=5.14$, $p<.01)$. As we anticipated, the injunctive appeal did not significantly differ from the control $(\mathrm{t}(111)=.20$, n.s.).

\section{Discussion}

The results of Study 1 support our goal-compatibility account. The combination of the activation of the collective level of self and normative messages (both injunctive and descriptive) is particularly effective in influencing attitudes toward grasscycling. In addition, the activation of the individual level of self is particularly effective in influencing attitudes when combined with either a benefit appeal or a descriptive appeal. Benefit appeals combined with the activation of the collective self and injunctive appeals combined with the activation of the individual self were less effective in positively influencing attitudes toward grasscycling, performing no better than an information-only control condition. This study builds on prior research that primes the level of self in a separate task (Gardner, Gabriel, and Lee 1999; White and Argo 2011) to show that priming of selfconstrual can also be accomplished effectively within the marketing communication itself.

While we believe that our results are due to a goalmatching mechanism, a possibility is that the effects emerge because our manipulations of level of self and appeal type are communicated within the same message context. As a result, some combinations might read more awkwardly than others (e.g., individual/injunctive condition). This view would suggest that lack of fluency (i.e., ease of understanding and processing meanings; Lee and Aaker 2004) rather than goal compatibility is driving the effects. To address this possibility, in Study 1, we included a measure of fluency (Lee and Aaker 2004) with which participants evaluated the message ("difficult to process/easy to process," "difficult to understand/easy to understand," and "difficult to comprehend/easy to comprehend"; seven-point scales; $\alpha=.94)$. We note that the interaction between level of self and appeal type did not predict fluency in this study $(\mathrm{F}(111)=.38$, n.s.), casting doubt on the possibility that fluency is driving the effects.

We also conducted a follow-up study $(n=127)$ in which we presented the priming of level of self and the message appeal manipulation as separate tasks. Participants first completed a task in which they circled words in a story that activated the individual or the collective self (for the procedure, see Study 3). Participants then viewed an advertisement that delivered the benefit appeal, the descriptive appeal, or the injunctive appeal. Finally, they completed the same measure of grasscycling attitudes that was completed in Study $1(\alpha=.94)$. The results of this study replicated Study 1's results. A level of self $\times$ message appeal ANOVA revealed the anticipated interaction $(\mathrm{F}(2,127)=8.36, p<$ $.001)$. When a collective level of self was activated, injunctive $(\mathrm{M}=5.51)$ and descriptive $(\mathrm{M}=4.93)$ appeals fared better than the benefit appeal $(\mathrm{M}=3.98$; $p \mathrm{~s}<.05)$. When the individual level of self was activated, participants reported more positive attitudes in response to the benefit $(\mathrm{M}=5.15)$ and the descriptive $(\mathrm{M}=4.95)$ appeal conditions than to the injunctive appeal condition $(\mathrm{M}=3.99 ; p \mathrm{~s}<.05)$. The finding that the same pattern and significance of results emerges using a methodology that separates the level of self and the appeal type manipulations also casts doubt on a fluency account of the results.

\section{Study 2: Field Data}

In Study 2, we extend the results of Study 1 by using a field study with the cooperation of a large metropolitan city to examine residents' actual grasscycling behaviors. Given that the key goal of promoting grasscycling activities is the reduction of waste going to landfills (Cobern et al. 1995), we measured decreases in residential disposal of grass waste in the garbage. We did so by recording actual wastedisposal behaviors of city residents both before and after the key intervention was given (which systematically varied both level of self and appeal type). Again, we propose that when the collective self is activated, consumers will be most responsive to injunctive and descriptive appeals, but when the individual self is activated, consumers will be most responsive to benefit and descriptive appeals.

\section{Method}

The second study involved a 2 (level of self: individual vs. collective) $\times 3$ (message appeal: descriptive norm vs. injunctive norm vs. self-benefit) experimental design, which also included a (no message) control condition, resulting in seven conditions. We used a pretest-posttest design, in which households' grasscycling behaviors were measured for three weeks before (T1) and three weeks after (T2) exposure to an appeal. We developed appeals in conjunction with the city to ensure that they were consistent with city branding. In cooperation with the city, we selected 676 households (between 92 and 104 for each condition) for participation in the project. In conjunction with city employees, data were recorded on whether garbage was placed out for collection, the total number of bags of garbage, how many bags containing grass were put out for garbage collection, and the size of the bags containing grass. To ensure reliability during data collection, city waste-management employees, who are familiar with the look and feel of grass, communicated to two research assistants the number of bags containing grass. As the research assistants traveled behind the garbage truck, they were able to visually calculate and record the remaining data. The research assistants were blind to the condition and hypotheses. A reduction in the number of bags of grass being put out for garbage collection between T1 and T2 suggests that the households are grasscycling rather than simply putting their grass out with the garbage. Previous research has validated this method of measuring grasscycling behavior (Cobern et al. 1995). Further data were gathered from 
municipal databases, including property land area and house square footage.

At T1, grasscycling activities were recorded once per week (on the day of garbage collection) for each household. After three weeks of pretest data collection, each household received one version of the marketing appeal, with the exception of the control condition, which received no appeal. Households were assigned to conditions in blocks of houses. The appeals were printed on door hangers and used recycled paper. The door hangers were consistent across conditions in their appearance and branding elements, with key information being varied according to each of the six conditions receiving appeals (see Appendix B). On one side of the door hanger, the level of self was manipulated as in Study 1. On the other side of the hanger, the message appeal was manipulated as in Study 1. Following distribution of the appeals, grasscycling activities were once again recorded for a period of three weeks (T2).

\section{Results}

We computed a difference score as the average grass collected at T1 minus the average grass collected at T2. Thus, lower scores represent less grass being disposed of in the garbage at T2 than at T1. For all analyses, we held as covariates land area and house square footage (which serve as proxies for total amount of available grass) and average size of garbage bags used for grass (to control for differences in bag size across households).

A 2 (level of self: individual vs. collective) $\times 3$ (message appeal: descriptive norm vs. injunctive norm vs. self-benefit) analysis of covariance revealed the predicted interaction $(\mathrm{F}(2,576)=3.27, p<.05)$. A one-way analysis of covariance across all conditions, including the control group, was also significant $(\mathrm{F}(6,666)=2.34, p<.05$; Figure 3$)$. As $\mathrm{H}_{1}$

\section{FIGURE 3}

\section{Reduction in Grass Left Out for Garbage Collection as a Function of Level of Self and Appeal Type}

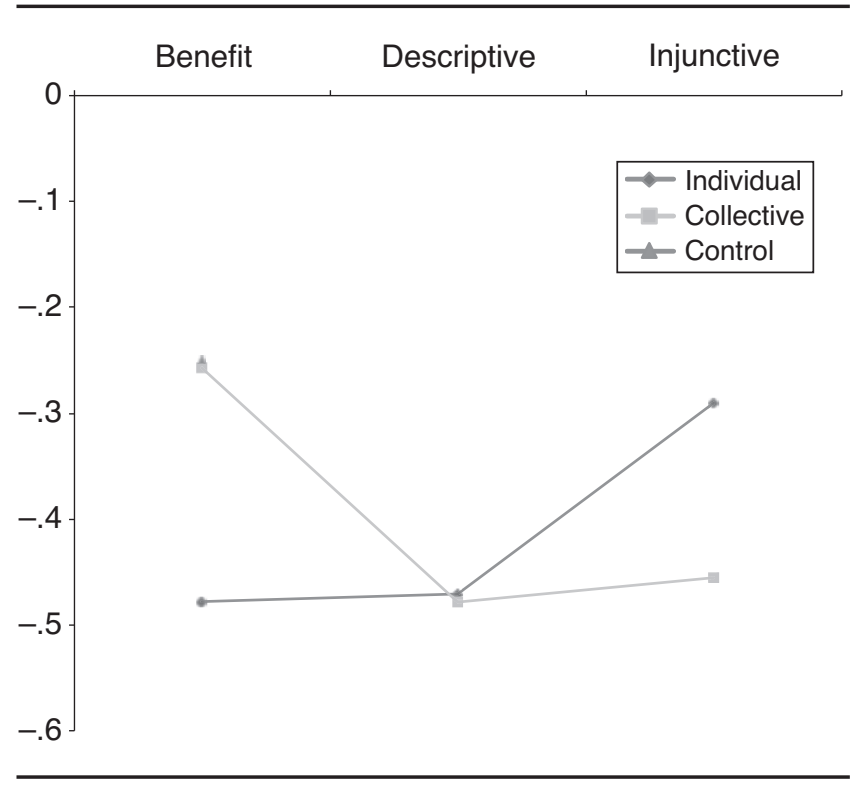

Notes: Scores reported are condition means. predicted, when a collective level of self was activated, the descriptive $(\mathrm{M}=-.479, \mathrm{SD}=.64 ; \mathrm{t}(666)=2.31, p<.05)$ and the injunctive $(\mathrm{M}=-.445, \mathrm{SD}=.66 ; \mathrm{t}(666)=2.06, p<$ $.05)$ appeals resulted in greater decreases in grass disposal at $\mathrm{T} 2$ than did the benefit appeal $(\mathrm{M}=-.257, \mathrm{SD}=.70)$. When the collective level of self was activated, both the descriptive and injunctive appeal conditions led to more positive actions than did the control condition $(\mathrm{M}=-.250$, $\mathrm{SD}=.73 ; p \mathrm{~s}<.05)$. As we anticipated, no differences between the benefit and control condition emerged $(\mathrm{t}=.09$, n.s.).

As $\mathrm{H}_{2}$ predicted, the individual/benefit-appeal condition led to decreased grass disposal $(\mathrm{M}=-.478, \mathrm{SD}=.72)$ compared with both the individual/injunctive appeal $(\mathrm{M}=-.290$, $\mathrm{SD}=.61 ; \mathrm{t}(666)=2.00, p<.05)$ and the control $(\mathrm{M}=-250$, $\mathrm{SD}=.73 ; \mathrm{t}(666)=2.34, p<.05)$ conditions. When the individual self was activated, the descriptive appeal $(\mathrm{M}=-.479$, $\mathrm{SD}=.79)$ fared better than the injunctive appeal $(\mathrm{M}=-.290$, $\mathrm{SD}=.62 ; \mathrm{t}(666)=1.97, p<.05)$ and the control $(\mathrm{M}=$ $-.250, \mathrm{SD}=.73 ; \mathrm{t}(666)=2.29, p<.05)$. In addition, as we anticipated, no differences emerged between the individual/ injunctive and the control conditions $(\mathrm{t}=.18$, n.s. $)$.

\section{Discussion}

The results of Study 2 again confirm that the combination of the activation of the collective level of self and either a descriptive norm or an injunctive norm is particularly effective in influencing grasscycling behaviors (as measured by decreased grass disposal in the garbage from T1 to T2). In addition, the combination of the individual level of self and the communication of benefits or descriptive norms positively predicts grasscycling behaviors. Importantly, we observed the least positive grasscycling actions when no information was provided to households (control condition), when benefits were communicated with a focus on the collective self (collective/benefit condition), and when injunctive messages were combined with a focus on the individual self (individual/injunctive condition).

\section{Study 3: The Moderating Role of Autonomy}

Study 3 had four major goals. First, we wanted to extend our inquiry into the domain of composting. Second, we wanted to prime level of the self in a separate task, to afford us greater experimental control. Third, we wanted to further explore the mechanisms underlying the divergent effects of injunctive versus descriptive norms when the independent self is activated. Consistent with our goal-compatibility account, we propose that when the individual self is activated, an injunctive norm represents a noncompatible goal. As we argued previously, this is because injunctive messages can threaten a person's sense of autonomy (i.e., felt ability to act and choose freely; Brehm 1966). Our goalcompatibility framework suggests that, given the nature of injunctive appeals, they will not be compatible with the activation of the individual level of self, leading to less positive composting intentions. A possibility, then, is that if this goal incompatibility can be reduced (i.e., if the threat to 
autonomy can be resolved in some way), these less favorable reactions to injunctive appeals when the individual self is activated can be mitigated. To enhance the generalizability of our findings, we tested our framework in the context of an on-campus composting program and predicted an interaction between autonomy and appeal type (when the individual self is activated). We thus anticipate that the ability to affirm autonomy will moderate the findings. Consistent with $\mathrm{H}_{2}$, when the individual self is activated and no opportunity to affirm autonomy is available, consumers will report decreased composting intentions in response to injunctive appeals, compared with benefit and descriptive appeals. Moreover, we predict the following:

$\mathrm{H}_{3}$ : When the individual self is activated and consumers are given the opportunity to affirm their autonomy (in a way that reduces goal incompatibility), differences in reported intentions between injunctive appeals compared with benefit and descriptive appeals are mitigated.

Importantly, our framework suggests that the opportunity to affirm autonomy should moderate the effects of appeal type on composting intentions among those whose individual self is activated but not among those whose collective self is activated. This is because those with the independent self activated are more sensitive to threats to selfindependence (White and Argo 2011). As such, when the collective level of the self is activated, no interaction between autonomy and appeal type should emerge.

The fourth goal of this study was to provide further evidence for our goal-compatibility mechanism. This view suggests that when the collective self is activated, otherfocused goals should predominate when either a descriptive or an injunctive appeal is presented. When the individual level of self is activated, self-focused goals should predominate when either a self-benefit or a descriptive appeal is presented. We test these predictions by coding participants' open-ended thought listings for both self- and other-focused thoughts. We propose that when the collective level of self is activated, a greater number of other-focused thoughts will be reported in response to appeals that match in terms of other-focused goals (descriptive appeals and injunctive appeals). When the individual level of the self is activated, more self-focused thoughts will be reported in response to appeals that match in terms of self-focused goals (benefit and descriptive appeals). Finally, we anticipate that when the collective self is activated, other-focused thoughts (but not self-focused thoughts) will mediate the effect of appeal type on composting intentions. When the individual self is activated, self-focused (but not other-focused) thoughts will mediate the effect of appeal type on composting intentions.

\section{Method}

Participants. Undergraduate students $(\mathrm{n}=358)$ took part in return for course credit. The study used a 2 (autonomy: neutral vs. autonomy affirmation) $\times 2$ (level of self: individual vs. collective) $\times 3$ (message appeal: descriptive norm vs. injunctive norm vs. self-benefit) experimental design.

Procedure. Upon arrival, participants were informed that they would be completing multiple tasks during the study session. Using a procedure that has been validated in past research (e.g., Brewer and Gardner 1996; Trafimow, Triandis, and Goto 1991; White and Argo 2011), we informed participants that the study was intended to obtain a measure of verbal competence, and they were invited to read a short story about which they answered questions later in the session. They were further told that to determine whether people are able to comprehend the story when they are distracted, they would be asked to circle pronouns appearing in the text of the short story. The texts in the two conditions differed only in the extent to which different pronouns were used: In the individual condition, "I" and "me" were used frequently, whereas in the collective condition, "we" and "us" were used.

In the next task, to manipulate autonomy, we asked participants to recall a past event. ${ }^{1}$ In the autonomy-affirmation condition, we asked them to think of a time when they felt high in autonomy. In the neutral condition, they recalled a neutral event (we adapted the neutral condition from McFarland, White, and Newth 2003; refer to Appendix C). Participants then viewed an advertisement regarding a new composting program on campus that communicated a descriptive appeal, an injunctive appeal, or a self-benefit appeal (see Appendixes C and D). Participants completed an open-ended thought listing: "We are interested in the thoughts that first come to mind when you think about composting. Just tell us your overall thoughts about composting." Later, we coded these responses for whether statements reflected an individual or a collective goal focus. For example, we coded statements such as "it is convenient for me" and "composting makes me feel good about myself" as individual-focused thoughts $(\mathrm{M}=1.37, \mathrm{SD}=1.09)$. In contrast, we coded statements such as "to do good for my community" and "composting is everyone's responsibility" as collective-focused thoughts $(\mathrm{M}=.62, \mathrm{SD}=.62)$. Two independent raters, who were blind to condition, coded the statements. Interrater reliability was high for individualfocused $(\alpha=.96)$ and collective-focused $(\alpha=.94)$ thoughts. Any disagreements were resolved through discussion, and we used the agreement ratings in the final analysis. Our key dependent measure was intentions toward composting on a series of seven-point scales: "How likely are you to take part in the University of _____ 's composting program?" "How inclined are you to take part in the University of 's composting program?" and "How willing are you to take part in the University of _____ 's composting program?" (adapted from White and Peloza 2009; $\alpha=$ $.88)$.

\footnotetext{
${ }^{1}$ To confirm the effectiveness of the autonomy manipulation, we conducted a pretest. Participants $(n=39)$ were given either the autonomy or the neutral version of the manipulation. They then answered the following questions: "To what extent do you feel autonomous?," "To what extent do you feel that you can be your own person?," "To what extent do you feel that you can make your own choices?," "To what extent do you feel that you can come to your own conclusions?," and "To what extent do you feel free to act as you choose?" $(\alpha=.91)$. The results revealed that those in the autonomous condition reporting feeling greater autonomy $(\mathrm{M}=$ 5.86) than did those in the neutral condition $(\mathrm{M}=4.69 ; \mathrm{t}(37)=$ $4.71, p<.001)$.
} 


\section{Results}

Composting intentions. An autonomy $\times$ level of self $\times$ message appeal ANOVA on composting intentions revealed the anticipated interaction $(\mathrm{F}(2,346)=5.59, p<.01)$. This three-way interaction qualified a level of self $\times$ appeal interaction $(\mathrm{F}(2,346)=10.21, p<.01)$. No other main effects or interactions were significant. When selecting for those primed with the individual self, a significant interaction between autonomy and appeal type emerged $(\mathrm{F}(2,213)=$ $8.50, p<.001)$. Consistent with $\mathrm{H}_{2}$, in the neutral-autonomy condition, those primed with an individual level of self reported lower composting intentions in response to the injunctive appeal $(\mathrm{M}=4.13, \mathrm{SD}=1.71)$ compared with both the benefit $(\mathrm{M}=5.56, \mathrm{SD}=1.23 ; \mathrm{t}(213)=4.83, p<.001)$ and descriptive $(\mathrm{M}=5.24, \mathrm{SD}=1.05 ; \mathrm{t}(213)=3.76, p<$ .001) appeals (Figure 4). However, as $\mathrm{H}_{3}$ predicted, when autonomy was affirmed, differences in intentions in response to the injunctive appeal $(\mathrm{M}=5.18, \mathrm{SD}=.99) \mathrm{com}$ pared with both the benefit $(\mathrm{M}=5.00, \mathrm{SD}=1.37 ; \mathrm{t}(213)=$ .51 , n.s. $)$ and descriptive $(\mathrm{M}=4.77, \mathrm{SD}=1.38 ; \mathrm{t}(213)=$ .71, n.s.) appeals were mitigated. Importantly, participants primed with the individual self reported significantly more

FIGURE 4

Interaction of Level of Self, Appeal Type, and Autonomy on Composting Intentions

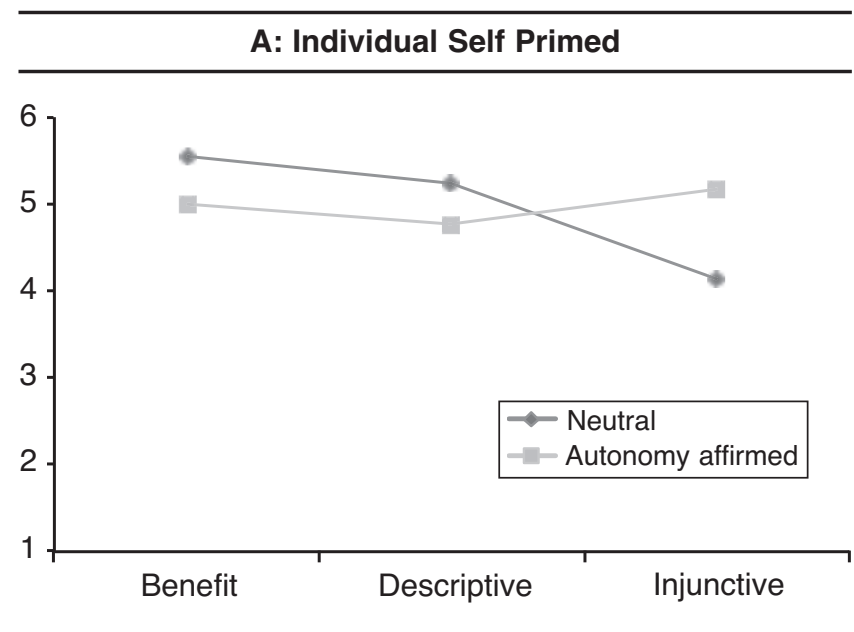

B: Collective Self Primed

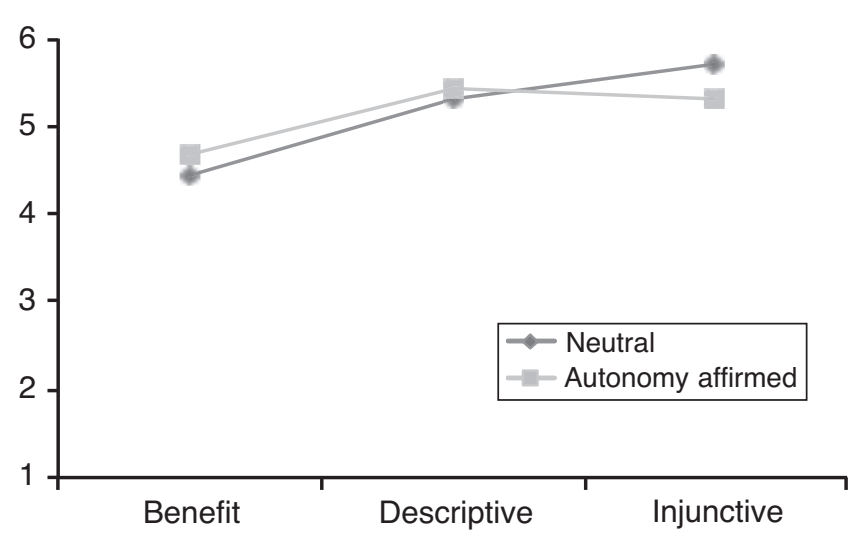

Notes: Scores reported are condition means. positive attitudes in response to the injunctive appeal when given the opportunity to affirm autonomy than under neutral conditions $(\mathrm{t}(213)=3.67, p<.001)$.

In addition, as we anticipated, when selecting for those primed with the collective self, no interaction between autonomy and appeal type emerged $(\mathrm{F}(2,133)=.75$, n.s. $)$. The main effect for autonomy was also not significant $(\mathrm{F}(2$, $133)=.02$, n.s.). As in the previous studies, the main effect for appeal type was statistically significant $(F(2,133)=$ $6.05, p<.01)$, indicating that more positive intentions were reported in response to the descriptive appeal $(\mathrm{M}=5.37)$ and the injunctive appeal $(\mathrm{M}=5.49)$ than to the benefit appeal $(\mathrm{M}=4.56$; ts $>2.24, p<.05)$. Thus, while appeal type influenced those primed with the collective self in the predicted ways, as we anticipated, the manipulation of autonomy did not influence those with the collective self primed.

Individual and collective thoughts. When selecting for those primed with the collective level of self, appeal type significantly predicted other-focused thoughts $(\mathrm{F}(1,133)=$ $6.29, p<.01)$ but not self-focused thoughts $\mathrm{F}(1,133)=$ $1.03, p>.35$; see Table 1). As we anticipated, when the collective level of self was primed, more other-focused thoughts were reported among those in the descriptive $(\mathrm{M}=.80, \mathrm{SD}=$ $.76)$ and the injunctive $(\mathrm{M}=.96, \mathrm{SD}=.85)$ appeal conditions than in the benefit appeal condition $(\mathrm{M}=.46, \mathrm{SD}=$ .47 ; ts $>2.34, p s<.05)$. Further analysis examined mediation using bootstrapping (Preacher and Hayes 2008; Zhao, Lynch, and Chen 2010). We conducted this analysis using an SPSS macro developed by Preacher and Hayes (2011) and employed appeal type as the independent variable, other-focused thoughts as the mediator, and composting intentions as the dependent variable. The analysis uses 5000 bootstrap resamples and a bias-corrected and bias-accelerated (BCa) 95\% confidence interval (Preacher and Hayes 2008).

TABLE 1

\section{Self- and Other-Focused Thoughts as a Function of Level of Self and Appeal Type (Study 3)}

\begin{tabular}{lcc}
\hline Dependent Variable/Prime/Appeal & $\mathbf{M}$ & SE \\
\hline Self-Focused Thoughts & & \\
$\quad$ Individual self & & \\
$\quad$ Benefit & & \\
$\quad$ Descriptive & $2.18_{\mathrm{a}}$ & .11 \\
$\quad$ Injunctive & $1.83_{\mathrm{a}}$ & .11 \\
Collective self & $1.16_{\mathrm{b}}$ & .10 \\
$\quad$ Benefit & & \\
$\quad$ Descriptive & $.93_{\mathrm{b}}$ & .13 \\
$\quad$ Injunctive & $.77_{\mathrm{b}}$ & .14 \\
Other-Focused Thoughts & $.75_{\mathrm{b}}$ & .14 \\
$\quad$ Individual self & & \\
$\quad$ Benefit & & \\
$\quad$ Descriptive & $.57_{\mathrm{a}}$ & .07 \\
$\quad$ Injunctive & $.47_{\mathrm{a}}$ & .07 \\
Collective self & $.57_{\mathrm{a}}$ & .06 \\
$\quad$ Benefit & $.46_{\mathrm{a}}$ & .08 \\
$\quad$ Descriptive & $.80_{\mathrm{b}}$ & .09 \\
Injunctive & $.95_{\mathrm{b}}$ & .09 \\
\hline
\end{tabular}

Notes: In each of the prime conditions, means with differing subscripts differ significantly at the .05 level. 
We obtained a $95 \%$ BCa bootstrap confidence interval of .0060 to .1973 . Given that zero was not included in the lower and upper bounds of this confidence interval (Preacher and Hayes 2008), this was an indication that other-focused thoughts had a significant indirect effect in the relationship between appeal type and composting intentions. Thus, as we anticipated, when the collective level of self was activated, other-focused thoughts mediated the effect of appeal type on composting intentions.

When selecting for those primed with the individual level of self, appeal type significantly predicted self-focused thoughts $(\mathrm{F}(2,213)=17.23, p<.001)$ but not other-focused thoughts $(\mathrm{F}(2,213)=.72$, n.s. $)$. As predicted, when the individual level of self was primed, a focus on the self was higher among those in the benefit $(\mathrm{M}=2.18, \mathrm{SD}=1.17)$ and the descriptive $(\mathrm{M}=1.84 ; \mathrm{SD}=1.12)$ appeal conditions than in the injunctive appeal condition $(\mathrm{M}=1.16, \mathrm{SD}=.96$; ts $>3.78, p<.001)$. We examined whether, when the level of the self was held constant at the individual, the effect of message appeal on intentions was mediated by self-focused thoughts. The results revealed that we obtained the $95 \%$ BCa bootstrap confidence interval of -.2348 to -.0483 . As such, our results show that self-focused thoughts had a significant indirect effect on the relationship between appeal type and composting intentions.

\section{Discussion}

Study 3 demonstrates that when the individual self is activated, the effect of appeal type on composting intentions is moderated by an autonomy manipulation. When autonomy is not affirmed, those primed at the individual level of the self report less positive composting intentions in response to injunctive appeals than to descriptive and benefit appeals. When the opportunity to affirm one's autonomy is available, the tendency for those with the individual self activated to respond relatively negatively to injunctive appeals is mitigated. These results suggest that when the individual level of self is primed, less positive reactions to injunctive appeals are due to perceived threats to autonomy.

Our results also provide additional evidence for a goalcompatibility account. When the collective self is activated, participants report significantly more other-focused thoughts in response to the injunctive and the descriptive appeals, compared with the benefit appeal. In contrast, when the individual self is activated, participants report more self-focused thoughts in response to the descriptive and benefit appeals, compared with the injunctive appeal. Importantly, when goals are more compatible, composting intentions are also more positive. Mediation analysis further supports the goal-compatibility account, revealing that other-focused (self-focused) thoughts mediate the effects when the collective (individual) self is primed.

\section{Study 4: The Role of Perceived Ambiguity}

The purpose of Study 4 is to further elucidate why, when the individual level of the self is activated, the responses to injunctive and descriptive appeals diverge. Study 3 high- lights the tendency for those with the individual self activated to respond negatively to injunctive appeals because such appeals can threaten individual autonomy. Study 4 focuses on why those primed with the individual self respond positively to descriptive appeals. At first glance, an individual level of self might seem goal incompatible with descriptive social norms. As noted in the beginning of this article, we propose that descriptive norms provide benefits to the self in the form of relevant information about how to behave appropriately (Cialdini and Trost 1998). Consistent with this informational view, descriptive norms should only strongly predict positive composting intentions when there is a need for such information. In particular, we suggest that while descriptive norms will provide this important informational value to the self when the activity is viewed as being ambiguous and unfamiliar, these effects will be mitigated when the activity is viewed as being relatively unambiguous. This is because in the latter case, descriptive information is less useful to the person because they are more likely to know how to behave appropriately. Notably, in a pretest, the behaviors of grasscycling and composting were viewed as being relatively ambiguous and unfamiliar. ${ }^{2}$ Because we were interested in the effects for those primed with the individual self, in Study 4, all participants completed an individual priming task, and we experimentally varied the degree of ambiguity associated with the activity (i.e., composting). We predict that when the individual self is activated, the effects proposed in $\mathrm{H}_{2}$ will again be replicated when the task is viewed as ambiguous. In particular, when the task is ambiguous, descriptive appeals will be evaluated more positively than injunctive appeals (and similarly to benefit appeals). In addition, we predict the following:

$\mathrm{H}_{4}$ : When the task is unambiguous, descriptive appeals are evaluated similarly to injunctive appeals (and less positively than benefit appeals).

\section{Method}

Participants. One hundred thirty-three undergraduate students took part in Study 4 in return for course credit. This study held the level of self constant at the individual level and used a 2 (ambiguity: high vs. low) $\times 3$ (message appeal: descriptive vs. injunctive vs. self-benefit) experimental design.

Procedure. Upon arrival, participants were informed that they would be completing multiple tasks during the study session. All participants completed the individual version of the self priming task (as in Study 3). Participants were then told that, to provide them with more information regarding composting, they would read a press release. In

\footnotetext{
${ }^{2}$ In a pretest, participants from the population of interest evaluated different activities on seven-point scales (e.g., "unclear/clear," "ambiguous/unambiguous," "uncertain/certain"). The results confirmed that participants viewed both our sustainable activities, grasscycling $(\mathrm{M}=2.86)$ and composting $(\mathrm{M}=3.13)$, as relatively unfamiliar and ambiguous compared with other consumer behaviors such as placing items in garbage $(M=6.45)$, bringing one's own coffee mug $(\mathrm{M}=6.00)$, recycling $(\mathrm{M}=5.85)$, and using reusable grocery bags $(\mathrm{M}=5.71$; all $p$ s $<.001)$.
} 
the high-ambiguity condition, the press release described the activity of composting in a way that was somewhat uncertain and ambiguous. In the low-ambiguity condition, the activity of composting was explained in more detail, thus providing clarity (Appendix $\mathrm{C}$ ). We confirmed the effectiveness of this manipulation with a pretest. 3 Participants then viewed the benefit appeal, the descriptive appeal, or the injunctive appeal from Study 3 and reported their composting intentions on the same scale used in Study 3 ( $\alpha=$ .87). Finally, to assess the effectiveness of the ambiguity manipulation, we asked participants to complete two items indicating (on seven-point scales) to what degree they viewed the activity of composting as being "clear" or "ambiguous."

\section{Results}

Manipulation check. A 2 (ambiguity: high vs. low) $\times 3$ (message appeal: descriptive norm vs. injunctive norm vs. self-benefit) ANOVA on the manipulation checks revealed only main effects for ambiguity such that composting was viewed as more clear in the low- $(\mathrm{M}=5.56)$ than the high$(\mathrm{M}=3.72)$ ambiguity condition $(\mathrm{F}(2,127)=42.79, p<$ .001). Similarly, composting was seen as being more ambiguous in the high-ambiguity condition $(\mathrm{M}=4.89)$ than the low-ambiguity condition $(\mathrm{M}=3.85 ; \mathrm{F}(2,127)=25.14$, $p<.0001)$.

Composting intentions. A 2 (ambiguity: high vs. low) $\times$ 3 (message appeal: descriptive norm vs. injunctive norm vs. self-benefit) ANOVA on composting intentions revealed the anticipated interaction $(\mathrm{F}(2,127)=3.23, p<.05)$. As we anticipated, when ambiguity was high, participants responded more positively to descriptive appeals $(\mathrm{M}=5.74$, $\mathrm{SD}=1.15)$ than to injunctive appeals $(\mathrm{M}=4.29, \mathrm{SD}=1.66$; $\mathrm{t}(127)=3.63, p<.001$; refer to Figure 5). In addition, when ambiguity was high, descriptive appeals were evaluated similarly to the benefit appeals $(\mathrm{M}=5.76, \mathrm{SD}=1.33$; $\mathrm{t}(127)=.05$, n.s.). As $\mathrm{H}_{4}$ predicted, when ambiguity was low, differences in intentions in response to the descriptive appeals $(\mathrm{M}=4.81, \mathrm{SD}=1.29)$ and injunctive appeals $(\mathrm{M}=$ $4.76, \mathrm{SD}=1.21)$ were mitigated $(\mathrm{t}(127)=.13$, n.s.). When ambiguity was low, composting intentions were lower in response to the descriptive appeals than to the benefit appeals $(\mathrm{M}=5.59, \mathrm{SD}=1.43 ; \mathrm{t}(127)=1.96, p<.05)$. Intentions in response to the descriptive appeals were higher when ambiguity was high $(\mathrm{M}=5.74, \mathrm{SD}=1.15)$ versus low $(\mathrm{M}=4.81, \mathrm{SD}=29 ; \mathrm{t}(127)=2.33, p<.05)$. Intentions in response to both injunctive and benefit appeals did not vary as a function of ambiguity (both $p s>.27$ ).

\footnotetext{
${ }^{3}$ In a pretest, participants $(n=42)$ read either the low- or highambiguity version of the press release and reported perceived ambiguity on six seven-point scales with higher numbers reflecting less ambiguity/more clarity (e.g., "unclear/clear," "ambiguous/ unambiguous," "uncertain/certain"). These items were answered regarding "What composting is" and "How to go about composting" (overall $\alpha=.92$ ). Analysis revealed that the high-ambiguity version was considered significantly more ambiguous/less clear $(\mathrm{M}=4.12)$ than the low-ambiguity version $(\mathrm{M}=5.53 ; \mathrm{t}=3.43$, $p<.001)$.
}

\section{FIGURE 5 \\ Composting Intentions as a Function of Ambiguity and Appeal Type (When the Individual Self is Primed)}

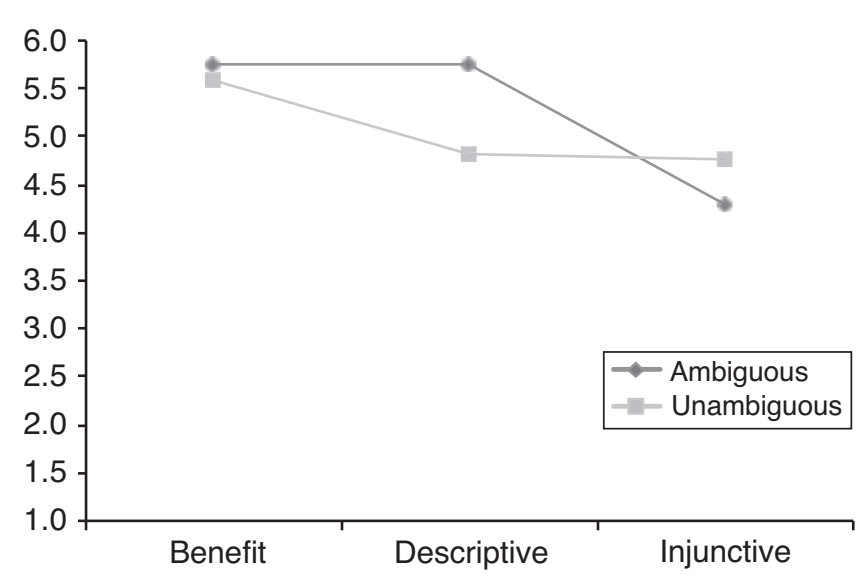

Notes: Scores reported are condition means, and all participants were primed with the individual level of self.

\section{Discussion}

The results of Study 4 suggest that descriptive appeals lead to positive intentions when the individual self is primed only when they provide important information to the self. When the individual self is activated, composting intentions in response to descriptive appeals are most positive when the activity is viewed as being somewhat ambiguous and, presumably, the descriptive norm can provide informational value. Under conditions in which the activity is unambiguous, descriptive appeals do not provide information of value to the self, and composting intentions are no longer more positive in response to descriptive versus injunctive appeals.

\section{General Discussion}

Taken together, the results across four studies highlight an important moderator of appeal type: whether the communication is considered at the individual or collective level of the self. This is true when level of self is manipulated through the wording in a marketing appeal (Studies 1 and 2) or a separate priming task (Study 1 posttest, Studies 3 and 4). The activation of the collective level of self paired with both descriptive and injunctive appeals is particularly effective. In addition, the combination of the individual level of self with the communication of benefits or descriptive norms positively predicts sustainable consumer attitudes, intentions, and behaviors. We observed the least positive sustainable outcomes in the control conditions and when there was a mismatch of goal compatibility in the communications - namely, when we combined injunctive messages with a focus on the individual self and when benefits were communicated with a focus on the collective self.

\section{Theoretical Implications of the Research}

The current research makes a theoretical contribution to extant research by highlighting a key moderator of normative influence: the level of the self at which the appeal is 
considered. In doing so, we highlight when normative appeals will be more and less effective than comparative appeals. The current research builds on work that suggests that injunctive norms are particularly powerful as behavioral directives (Cialdini, Reno, and Kallgren 1990; Kallgren, Reno, and Cialdini 2000; Reno, Cialdini, and Kallgren 1993) by showing the conditions under which injunctive norms will be less effective than other appeals, such as those employing descriptive norms or information about benefits to the self. Of importance, we propose and find evidence for a goal-compatibility mechanism for the effects. In particular, when both the collective (individual) self is activated and an injunctive or a descriptive (a benefit or a descriptive) appeal is presented, salient collective(individual-) level goals will be congruent. This extends prior work that highlights matching effects in the domains of regulatory focus (e.g., whether a prevention or promotion focus is activated; Lee and Aaker 2004) and construal level (e.g., whether the activity is considered at a lower-level concrete construal or at a higher-level abstract construal; White, MacDonnell, and Dahl 2011), by showing that a match in terms of individual versus collective goals can also have positive downstream consequences.

Importantly, we identify the mechanisms underlying the relatively negative effects of injunctive appeals and the positive effects of descriptive appeals when the individual self is activated. The evidence suggests that when the individual self is primed, injunctive appeals are threatening to a person's sense of autonomy. Indeed, the introduction of a condition under which people are able to affirm their autonomy mitigates the unfavorable effects of injunctive appeals for those with the individual level of self activated. In addition, the positive effects of descriptive appeals under conditions in which the individual self is activated appear to be driven by the self-benefit of informational value. When the activity is viewed as ambiguous (and the informational value of descriptive norms is high), composting intentions are higher in response to descriptive than to injunctive appeals. In contrast, when the activity is viewed as unambiguous (the informational value of descriptive norms is low), composting intentions in response to descriptive appeals are similar to those in response to injunctive appeals. In examining the moderating roles of both autonomy and ambiguity, we identify important boundary conditions for the observed effects.

Our work also clarifies and builds on recent work that has identified differential responses to descriptive and injunctive norms (Jacobson, Mortensen, and Cialdini 2010). Consistent with Jacobson, Mortensen, and Cialdini's (2010, p. 433) conceptualization, we propose that descriptive norms and injunctive norms relate to fundamentally distinct goals - "making accurate/efficient decisions" and "gaining social approval," respectively. Importantly, we show that activating the individual level of self can make the accuracy component of descriptive norms more compelling and the "ought" nature of injunctive norms more threatening to autonomy. In contrast, activating the collective self appears to make the social nature of both injunctive and descriptive norms more salient. We offer an additional point of divergence from Jacobson, Mortensen, and Cialdini: they propose that injunctive norms can also provide an informational/ accuracy function; however, we did not find evidence that injunctive norms are more effective when the situation is viewed as more versus less ambiguous. Further research could examine in more detail whether there are conditions under which injunctive norms can serve an informational function.

\section{Managerial Implications}

\author{
"You Can Do This"-Weekend to End Breast Cancer \\ "Together We Can Make Cancer History"-Canadian \\ Cancer Society
}

The preceding quotations demonstrate that when appealing to consumers to engage in prosocial actions, marketers often take one of two routes: they can focus on the role the individual plays in effecting change, or they can focus on the role of the collective or group. The current work highlights the conditions under which using these two routes might be more (or less) effective. Foremost, our results suggest that marketing communications should ensure a match in terms of goal compatibility. This involves concurrently activating the collective self and making injunctive or descriptive normative appeals or activating the individual self and making benefit or descriptive appeals to consumers. Of importance, the current work demonstrates to marketing practitioners that no type of appeal has uniformly positive effects and that a mismatch of appeal type with the level of self activated can lead to lower levels of positive sustainable consumer behaviors.

From a practical standpoint, we provide insight into how to craft effective appeals by highlighting how marketing practitioners might activate a particular level of self through marketing communications. Our field study, conducted in cooperation with a metropolitan city, shows that these manipulations can influence actual consumer behaviors. Given that consumers must filter through a large number of promotional materials every day, it is telling that our manipulation, delivered on a single occasion, influenced participation in a sustainable behavior. Thus, we highlight actionable ways that marketers can influence consumer activation of different levels of the self to make normative appeals more successful.

Our findings regarding the moderating role of autonomy also have important implications for marketers. If the marketer needs to communicate an injunctive message to a target market that likely includes more independent consumers, a possible strategy is to also affirm the consumer's autonomy in some way. This could be done within the marketing communication itself or by empowering consumers to assert their autonomy. For example, taglines such as "It's Your Choice" or "You Decide" might increase consumer autonomy in the context of an advertisement.

In addition, the moderating role of ambiguity has practical implications for marketers. The results of Study 4 suggest to marketers that the combination of the activation of the individual self and a descriptive appeal can be particularly effective in influencing positive consumer intentions, but only under specific circumstances. If the activity or behavior is perceived as ambiguous or unfamiliar, consumers with the independent self activated will likely 
respond positively to descriptive appeals. However, if the situation is unambiguous (and the informational value of descriptive norms is diminished), the combination of the activation of the individual self and a descriptive norm may not be as effective in encouraging positive intentions and behaviors. Thus, if marketers are promoting an activity that is uncertain or ambiguous, using an appeal that activates the individual self and provides descriptive normative information might be particularly effective.

In a society in which encouraging sustainable consumer behaviors is becoming increasingly important, the current findings converge on important practical implications for both marketers and policy makers aiming to encourage relatively unfamiliar sustainable consumer behaviors. While many sustainable behavioral options are available to consumers in today's market, technology has moved faster than consumer uptake in many domains because consumers have been slow to adopt many of these alternatives. Marketers developing campaigns to encourage consumers to demand alternative forms of energy, buy hybrid vehicles, purchase carbon offsets, or boycott unsustainable alternatives might do well to match the level of the self activated with the appeal type when crafting communications.

\section{Directions for Further Research}

Further research could examine moderators of the reactions to different types of appeals on the part of those whose collective level of self is activated. For example, the role of the reference group implied in the marketing communication might be examined. When the communication is considered at the collective level of the self, consumers might be more responsive to descriptive appeals that feature highly relevant groups (e.g., neighbors on one's own street) than similar appeals that feature less relevant groups (e.g., residents on a street in another city). In addition, researchers could further examine the processes underlying the relatively negative responses to benefit appeals on the part of those with the collective self activated.

The current research purposefully focuses on sustainable consumer behaviors that are somewhat unfamiliar and ambiguous to consumers. This allowed us to show real- world examples of when descriptive and injunctive appeals would lead to divergent consumer responses. Of note, these divergent responses to descriptive and injunctive social norms would likely emerge in other domains in which the action is ambiguous (e.g., perhaps in the domain of new technology adoption). Moreover, our findings in support of goal compatibility would likely emerge in other domains as well. For example, if Coca-Cola were to prime the individual self, it is likely that self-benefit appeals (that focus on attributes such as taste and quality) would be more effective than normative appeals (that focus on what other people are doing). In contrast, if the collective level of self were activated, normative appeals would likely be more persuasive than communication focusing on benefits to the self. Further research could generalize the effects observed in the current research to other contexts.

In addition, researchers could examine other moderators of the reactions of those with the individual level of self activated in response to injunctive appeals. For example, when the individual self is activated, would the framing of the message influence consumer responses? A possibility is that framing an injunctive norm positively (i.e., by highlighting the positive consequences of engaging in the behavior) would lead to less reactance than framing it negatively (by highlighting the negative consequences of engaging in the behavior).

The current research illustrates that, in the design of marketing communications, not only is the appeal type influential on its own, but the means by which the appeal is communicated is also important. Further research could examine other ways to highlight the individual versus the collective level of the self-for example, by making the appeals in either a public or private setting (White and Peloza 2009). Exploring this line of thought could ultimately provide those designing marketing communications with a toolbox for selecting ways to most effectively match the goal compatibility of communication elements within normative appeals. Taken together, the current research represents an important step in identifying actionable ways in which marketers can appeal to consumers to engage in sustainable behaviors.

\section{REFERENCES}

Brehm, Jack W. (1966), A Theory of Psychological Reactance. New York: Academic Press.

Brehm, Sharon S. and Jack W. Brehm (1981), Psychological Reactance: A Theory of Freedom and Control. New York: Academic Press.

Brewer, Marilynn B. (1991), "The Social Self: On Being the Same and Different at the Same Time," Personality and Social Psychology Bulletin, 17 (5), 475-82.

— and Wendi Gardner (1996), "Who Is This 'We'? Levels of Collective Identity and Self-Representations," Journal of Personality and Social Psychology, 71 (1), 83-93.

Brunel, Frederic F. and Michelle R. Nelson (2000), "Explaining Gendered Responses to 'Help-Self' and 'Help-Others' Charity Ad Appeals: The Mediating Role of World-Views," Journal of Advertising, 29 (3), 15-28.

Cialdini, Robert B. (2001), Influence: Science and Practice, 4th ed. Boston: Allyn \& Bacon.
, Carl A. Kallgren, and Raymond R. Reno (1991), “A Focus Theory of Normative Conduct: A Theoretical Refinement and Reevaluation of the Role of Norms in Human Behavior," in Advances in Experimental Social Psychology, Vol. 24, Mark Zanna, ed. New York: Academic Press, 201-234.

— , Raymond R. Reno, and Carl A. Kallgren (1990), “A Focus Theory of Normative Conduct: Recycling the Concept of Norms to Reduce Littering in Public Places," Journal of Personality and Social Psychology, 58 (2), 1015-26.

- and Melanie R. Trost (1998), "Social Influence: Social Norms, Conformity and Compliance," in The Handbook of Social Psychology, Vols. 1 and 2, 4th ed., Daniel T. Gilbert, Susan T. Fiske, and Gardner Lindzey, eds. New York: McGraw-Hill, 151-92.

Cobern, Melissa K., Brian E. Porter, Frank C. Leeming, and William O. Dwyer (1995), "The Effect of Commitment on Adoption and Diffusion of Grass Cycling," Environment and Behavior, 27 (2), 213-32. 
Costanzo, Mark, Dane Archer, Elliot Aronson, and Thomas Pettigrew (1986), "Energy Conservation Behavior: The Difficult Path from Information to Action," American Psychologist, 41 (5), 521-28.

Fisher, Robert J. and David Ackerman (1998), "The Effects of Recognition and Group Need on Volunteerism: A Social Norm Perspective," Journal of Consumer Research, 25 (3), 262-75.

Gardner, Wendi L., Shira Gabriel, and Angela Y. Lee (1999), “'I' Value Freedom but 'We' Value Relationships: Self-Construal Priming Mirrors Cultural Differences in Judgment," Psychological Science, 10 (4), 321-26.

Goldstein, Noah J., Robert B. Cialdini, and Vladas Griskevicius (2008), "A Room with a Viewpoint: Using Social Norms to Motivate Environmental Conservation in Hotels," Journal of Consumer Research, 35 (3), 472-82.

Griskevicius, Vladas, Noah J. Goldstein, Chad R. Mortensen, Robert B. Cialdini, and Douglas T. Kenrick (2006), "Going Along Versus Going Alone: When Fundamental Motives Facilitate Strategic (Non)Conformity," Journal of Personality and Social Psychology, 91 (2), 281-94.

Holmes, John G., Dale T. Miller, and Melvin J. Lerner (2002), "Committing Altruism Under the Cloak of Self-Interest: The Exchange Fiction," Journal of Experimental Social Psychology, 38 (2), 144-51.

Howell, D.C. (1997), Statistical Methods for Psychology, 4th ed. Belmont, CA: Wadsworth Publishing Company.

Jacobson, Ryan P., Chad R. Mortensen, and Robert B. Cialdini (2011), "Bodies Obliged and Unbound: Differentiated Response Tendencies for Injunctive and Descriptive Social Norms," Journal of Personality and Social Psychology, 100 (3), 433-48.

Kallgren, Carl A., Raymond R. Reno, and Robert B. Cialdini (2000), "A Focus Theory of Normative Conduct: When Norms Do and Do Not Affect Behaviours," Personality and Social Psychology Bulletin, 26 (8), 1002-1012.

Lee, Angela Y. and Jennifer L. Aaker (2004), "Bringing the Frame into Focus: The Influence of Regulatory Fit on Processing Fluency and Persuasion," Journal of Personality and Social Psychology, 86 (2), 205-218.

—, , and Wendi L. Gardner (2000), "The Pleasures and Pains of Distinct Self-Construals: The Role of Interdependence in Regulatory Focus," Journal of Personality and Social Psychology, 78 (6), 1122-34.

Liu, Jia (Elke), Dirk Smeesters, and Kathleen D. Vohs (2012), "Reminders of Money Elicit Feelings of Threat and Reactance in Response to Social Influence," Journal of Consumer Research, 38 (April), 1030-46.

Luchs, Michael G., Rebecca Walker Naylor, Julie R. Irwin, and Rajagopal Raghunathan (2010), "The Sustainability Liability: Potential Negative Effects of Ethicality on Product Preference," Journal of Marketing, 74 (September), 18-31.

Markus, Hazel R. and Shinobu Kitayama (1991), "Culture and the Self: Implications for Cognition, Emotion, and Motivation," Psychological Review, 98 (2), 224-53.

McFarland, Cathy and Dale T. Miller (1994), "The Framing of Relative Performance Feedback: Seeing the Glass as Half Empty or Half Full," Journal of Personality and Social Psychology, 66 (6), 1061-73.

—_ Katherine White, and Sarah Newth (2003), "Mood Acknowledgement and Correction for the Mood-Congruency Bias in Social Judgment," Journal of Experimental Social Psychology, 39 (5), 483-91.

Menon, Ajay and Anil Menon (1997), "Enviropreneurial Marketing Strategy: The Emergence of Corporate Environmentalism as Market Strategy," Journal of Marketing, 61 (January), 51-67.
Mick, David G. (2006), "Meaning and Mattering Through Transformative Consumer Research," in Advances in Consumer Research, Vol. 33, Cornelia Pechmann and Linda L. Price, eds. Provo, UT: Association for Consumer Research, 297-300.

Nolan, Jessica M., Wesley P. Schultz, Robert B. Cialdini, Noah J. Goldstein, and Vladas Griskevicius (2008), "Normative Social Influence Is Underdetected," Personality and Social Psychology Bulletin, 34 (7), 913-23.

OOECD (2008), Promoting Sustainable Consumption. Paris: OECD Publications.

Peattie, Ken (2011), "Green Consumption: Behavior and Norms," Annual Review of Environment and Resources, 35, 195-228.

Preacher, Kristopher J. and Andrew F. Hayes (2008), “Asymptotic and Resampling Strategies for Assessing and Comparing Indirect Effects in Simple Mediation Models," Behavior Research Methods, 40 (3), 879-91.

— and (2011), "My Macros and Code for SPSS and SAS," (accessed November 16, 2012), [available at http:// www.afhayes.com/spss-sas-and-mplus-macros-and-code.html].

Reno, Raymond R., Robert B. Cialdini, and Carl A. Kallgren (1993), "The Transsituational Influence of Social Norms," Journal of Personality and Social Psychology, 64 (1), 104-112.

Schultz, Wesley P., Jessica M. Nolan, Robert B. Cialdini, Noah J. Goldstein, and Vladas Griskevicius (2007), "The Constructive, Destructive, and Reconstructive Power of Social Norms," Psychological Science, 18 (5), 429-34.

Singelis, Theodore M. (1994), "The Measurement of Independent and Interdependent Self-Construals," Personality and Social Psychology Bulletin, 20 (October), 580-91.

Smith, Joanne R. and Winnifred R. Louis (2008), "Do As We Say and as We Do: The Interplay of Descriptive and Injunctive Group Norms in the Attitude-Behaviour Relationship," British Journal of Social Psychology, 47 (December), 647-66.

Tajfel, Henri and John C. Turner (1986), The Social Identity Theory of Intergroup Behavior. Chicago: Nelson-Hall.

Trafimow, David, Harry C. Triandis, and Sharon G. Goto (1991), "Some Tests of the Distinction Between the Private Self and the Collective Self," Journal of Personality and Social Psychology, 60 (5), 649-55.

Triandis, Harry C. (1989), "The Self and Social Behavior in Differing Cultural Contexts," Psychological Review, 96 (3), 506-520.

U.S. EPA (2011), Municipal Solid Waste in the United States: Facts and Figures 2009. Washington, DC: U.S. EPA.

White, Katherine and Jennifer J. Argo (2011), "When Imitation Doesn't Flatter: The Role of Consumer Distinctiveness in Response to Mimicry," Journal of Consumer Research, 38 (December), 667-80.

and Darren W. Dahl (2006), "To Be or Not Be: The Influence of Dissociative Reference Groups on Consumer Preferences," Journal of Consumer Psychology, 16 (4), 404-413.

, Rhiannon MacDonnell, and Darren W. Dahl (2011), "It's the Mind-Set that Matters: The Role of Construal Level and Message Framing in Influencing Consumer Efficacy and Conservation Behaviors," Journal of Marketing Research, 48 (June), 472-85. - and John Peloza (2009), "Self-Benefit Versus Other-Benefit Marketing Appeals: Their Effectiveness in Generating Charitable Support," Journal of Marketing, 73 (July), 109-124.

World Wildlife Fund (2012a), "Earth Hour Campaign," (accessed April 2012), [available at http://www.worldwildlife.org/sites/ earthhour/index.html].

— (2012b), "Earth Hour Campaign on Facebook," (accessed April 2012), [available at https://www.facebook.com/\#!/worldwildlifefund].

Zhao, Xinshu, John G. Lynch Jr., and Qimei Chen (2010), "Reconsidering Baron and Kenny: Myths and Truths About Mediation Analysis," Journal of Consumer Research, 37 (2), 197-206. 


\section{APPENDIX A \\ Wording of Appeals in Studies 1 and 2}

\begin{abstract}
Condition
Individual/Injunctive

How can you, as an

individual, make a

difference? You can

make a difference by

grasscycling.
\end{abstract}

Individual/Descriptive

How can you as an

individual make a

difference? You can

make a difference by

grasscycling.

\section{Individual/Benefit}

How can you, as an individual, make a difference? You can make a difference by grasscycling.

\section{Collective/Injunctive How can we as a community make a difference? We can make a difference by grasscycling.}

\section{Collective/Descriptive How can we as a community make a difference? We can make a difference by grasscycling.}

\section{Collective/Benefit}

How can we as a community make a difference? We can make a difference by grasscycling.

\section{Information Only: Study 1}

How can a difference be made? A difference can be made by grasscycling.
Appeal

Why should you grasscycle? A recent survey suggests that as an individual you can reduce the amount of waste going to the landfill in the summer months by grasscycling. Approximately 37 percent of what you put in the trash during the growing season is yard waste, which is mostly grass clippings. Your neighbors want you to grasscycle. Grasscycling is something you should do for your community. You should grasscycle because it has positive implications for the environment-it reduces the amount of fertilizer and water you need to use on your lawn. You should make a positive contribution to our community by grasscycling.

Why should you grasscycle? A recent survey suggests that as an individual you can reduce the amount of waste going to the landfill in the summer months by grasscycling. Approximately 37 percent of what you put in the trash during the growing season is yard waste, which is mostly grass clippings. Your neighbors are grasscycling. You can too. Think about how you can join in and grasscycle. Join others in your community in grasscycling this spring and summer. Most people in your community are finding ways to reduce the materials that are going to the landfillyou can contribute by grasscycling.

Why should you grasscycle? A recent survey suggests that as an individual you can reduce the amount of waste going to the landfill in the summer months by grasscycling. Approximately 37 percent of what you put in the trash during the growing season is yard waste, most of which is grass clippings. Think about the benefits for you as an individual if you grasscycle. Grass cycling improves your lawn quality. Grasscycling reduces the amount of fertilizer and water you need to use on your lawn. Think of the time you can save on your yard work. With no raking involved, grasscycling can reduce the amount of time and work your yard requires.

Why should we grasscycle? A recent survey suggests that as a community we can reduce the amount of waste going to the landfill in the summer months by grasscycling. Approximately 37 percent of what we put in the trash during the growing season is yard waste, most of which is grass clippings. Our neighbors want us to grasscycle. Grasscycling is something we should do for our community. We should grasscycle because it has positive implications for the environment - it reduces the amount of fertilizer and water we need to use on our lawns. We should make a positive contribution to our community by grasscycling.

Why should we grasscycle? A recent survey suggests that as a community we can reduce the amount of waste going to the landfill in the summer months by grasscycling. Approximately 37 percent of what we put in the trash during the growing season is yard waste, most of which is grass clippings. Our neighbors are grasscycling. Think about how we can all join in and grasscycle. Join others in our community in grasscycling this summer. Most people in our community are findings ways to reduce the materials that are going to the landfill-we can contribute by grasscycling.

Why should we grasscycle? A recent survey suggests that as a community we can reduce the amount of waste going to the landfill in the summer months by grasscycling. Approximately 37 percent of what we put in the trash during the growing season is yard waste, most of which is grass clippings. Think about the benefits for our community if we grasscycle. Grasscycling improves our lawn quality. Grasscycling reduces the amount of fertilizer and water we need to use on our lawns. Think of the time we can save on our yard work. With no raking involved, grasscycling can reduce the amount of time and work our yards require.

Grasscycling is the natural recycling of grass by leaving grass clippings on the lawn after mowing. Grass clippings will quickly decompose, returning valuable nutrients to the soil. A recent survey suggests that the amount of waste going to the landfill in the spring and summer months can be reduced by grasscycling. Up to $37 \%$ of what you put in the trash during the growing season is yard waste, most of which is grass clippings.

Notes: In Study 2, the control condition provided no information to participants. 


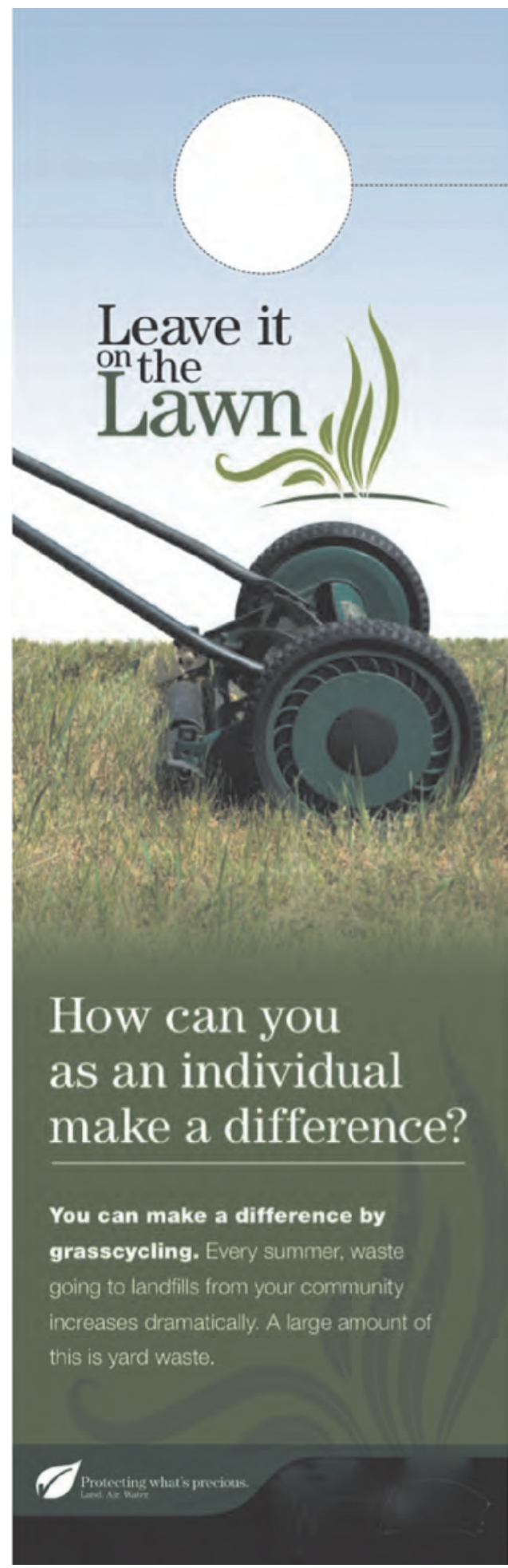

Individual/Injunctive Norm

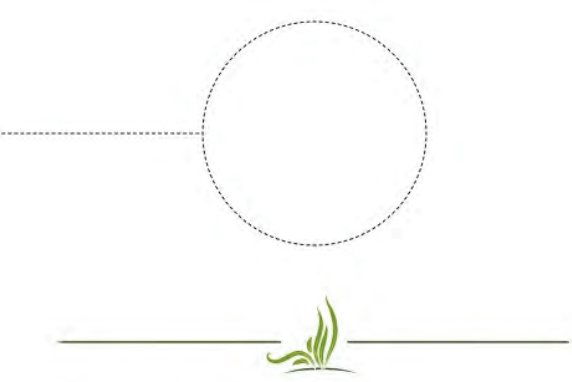

Grass clippings.

Leave them on the lawn.

Grasscycling is the natural recycling of grass by leaving clippings on the lawn after mowing. Grass clippings will quickly decompose, returning valuable nutrients to the soil.

Why should you grasscycle?

A recent survey suggests that as an individual you can reduce the amount of waste going to the landfill in the summer months by grasscycling. Approximately 37 per cent of what you put in the trash during the growing season is yard waste, most of which is grass clippings.

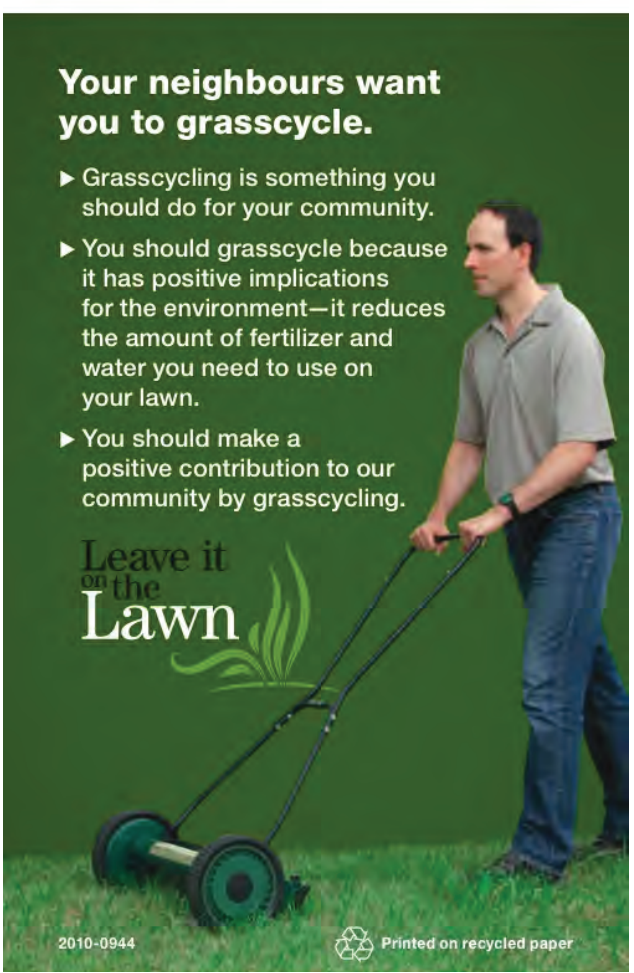

Individual/Injunctive Norm 


\section{Appendix C Wording of Manipulations in Studies 3 and 4}

\section{Appeal Type Manipulation (Studies 3 and 4)}

Benefit Appeal

Think about the benefits of composting.

Organic waste comprises about one third of garbage created. Composting results in decreased costs for campus waste removal, keeping tuition costs from rising.

With healthy soil, it's possible to enjoy the social, economic, and environmental benefits that growing flowers, plants, and food can bring-it's easy to feel good about composting.

\section{Descriptive Appeal}

Friends and colleagues on campus are composting too.

Join others in the campus community in composting this semester!

Most people in the campus community are finding ways to reduce the materials that are going to the landfill. One way to contribute is by composting!

\section{Injunctive Appeal}

Friends and colleagues on campus want everyone to compost.

Composting is something that should be done for the campus community.

Everyone should compost because it has positive implications for the environment-it will reduce the amount of waste going to the landfill.

\section{Autonomy Manipulation (Study 3)}

\section{Autonomy Condition}

You will be asked to recall an experience related to feelings of autonomy. We define autonomy as the opportunity to be your own person and to be directed by your own considerations and desires, rather than by conditions or circumstances that are simply externally imposed upon you. That is, autonomy reflects the opportunity to make your own choices and conclusions, without feeling like these were forced upon you by external constraints. In the space below, please describe a moment in your life in which you can recall feeling particularly high in autonomy:

\section{Neutral Condition}

You will be asked to recall an experience that is particularly neutral in nature. A neutral event is one in which something mundane or "everyday" happened to you (e.g., walking through the mall, going to the bank, a day at school, etc.). Try to describe an event that was neither particularly pleasant nor particularly unpleasant (i.e., an emotionally neutral event). In the space below, please describe a moment in your life that was particularly neutral and mundane in nature:

\section{Ambiguity Manipulation (Study 4)}

\section{High-Ambiguity Condition}

The Office of Sustainability at the University of $\mathrm{X}$ is excited to announce that a new waste management infrastructure, including facilities to deal with organics, will be
APPENDIX D

Example of Marketing Materials, with

Campus Branding Removed (Descriptive Norm Appeal Condition)

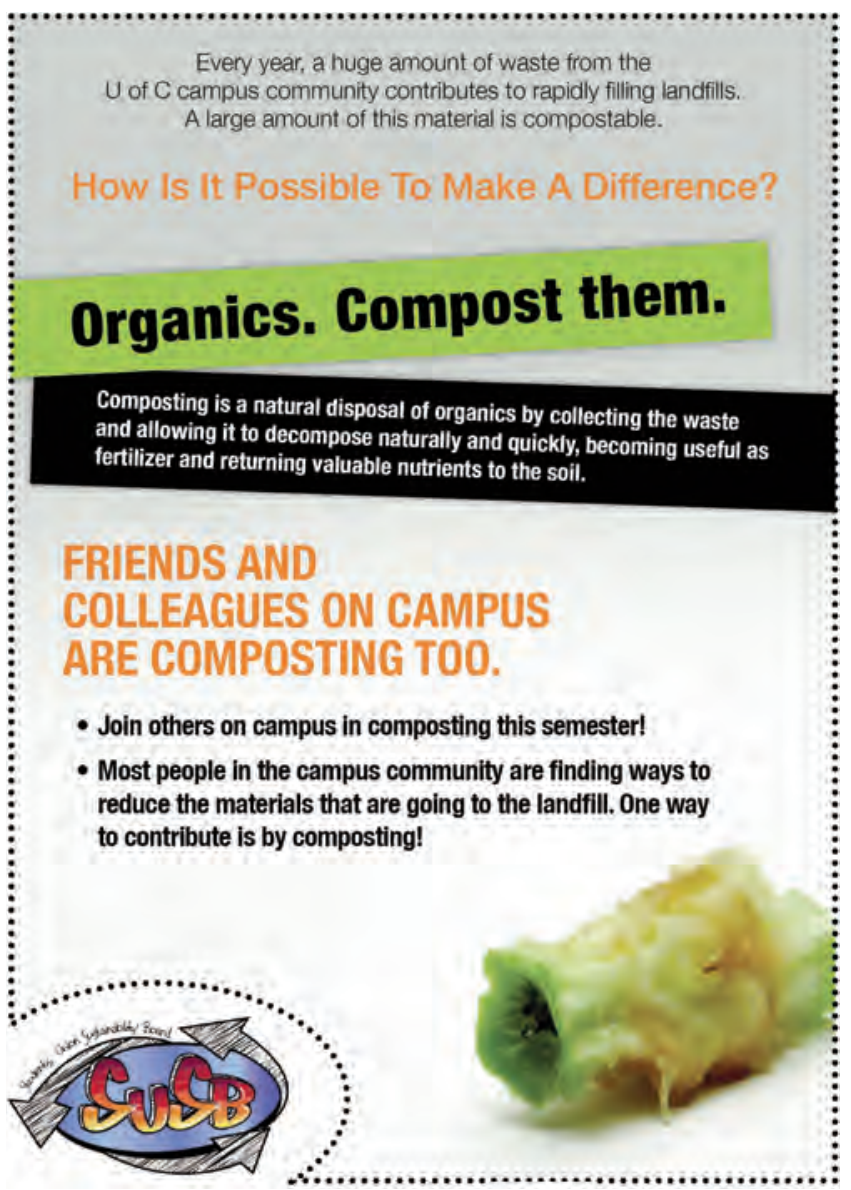

in place on campus for fall semester 2011. The decision to implement new composting infrastructure follows a comprehensive study completed by the Office of Sustainability, which examined waste diversion behaviours on campus. In the hopes of increasing the frequency of composting on campus, the Office of Sustainability will be working throughout the next year to provide education on composting on campus.

Composting is sometimes viewed by people as being a somewhat ambiguous activity due to the many different types of composting that exist and the different processes through which decomposition can take place. In addition, there is variation in the types and ratios of materials accepted across different facilities. The campus currently has two different programs operating for composting, preand post-consumer organics.

\section{Low-Ambiguity Condition}

The Office of Sustainability at the University of $\mathrm{X}$ is excited to announce that a new waste management infrastructure, including composting bins, will be in place on campus for fall semester 2011. Composting is a natural means for disposing of organic materials (i.e., food, leaves, lawn waste). By collecting organic waste and allowing it to decompose naturally and quickly, compost as an end prod- 
uct becomes useful as fertilizer and returns valuable nutrients to the soil. Students just need to be aware of what materials they can compost on campus - fruits, vegetables, all grains (including bread, rice, noodles, etc.), tea bags, coffee grounds, compostable cups, and any other plantbased materials (leaves and grass) can go into the blue compost bins.

At the university level, organic materials are deposited in an in-vessel composter on campus called an 'earth tub,' that can process up to 18 tonnes of organic materials annually by combining the right levels of moisture, materials, and air circulation for an efficient process. Once completely broken down, the 'compost' is returned to the grounds to fertilize campus greenspaces. The campus currently has two different programs operating for composting. Pre-consumer organics are collected from more than 20 vendors across campus, while post-consumer organics are collected in food courts and dining areas. 
Copyright of Journal of Marketing is the property of American Marketing Association and its content may not be copied or emailed to multiple sites or posted to a listserv without the copyright holder's express written permission. However, users may print, download, or email articles for individual use. 